\title{
The Maturity of Humanitarian Logistics against Recurrent Crises
}

\author{
Jesus Gonzalez-Feliu ${ }^{1, *}$, Mario Chong ${ }^{2}{ }^{\mathbb{D}}$, Jorge Vargas-Florez ${ }^{3}\left(\mathbb{D}\right.$, Irineu de Brito Jr. ${ }^{4}(\mathbb{D}$, \\ Carlos Osorio-Ramirez ${ }^{5}$, Eric Piatyszek ${ }^{6}$ and Renato Quiliche Altamirano ${ }^{2}$ (i) \\ 1 Supply Chain, Purcahsing and Project Management Department, Excelia Group, \\ La Rochelle Business School, 17000 La Rochelle, France \\ 2 Engineering Department, Universidad del Pacifico, Lima 15072, Peru; m.chong@up.edu.pe (M.C.); \\ r.quilichealtamirano@up.edu.pe (R.Q.A.) \\ 3 Engineering Department, Pontifica Universidad Católica del Peru, Lima 15088, Peru; \\ jorge.vargas@pucp.edu.pe \\ 4 Environmental Engineering Department, Sao Paulo State University, São José dos Campos 12247-004, Brazil; \\ irineu.brito@unesp.br \\ 5 School of Business and Public Accounting, Faculty of Economic Sciences, \\ Universidad Nacional de Colombia, Bogotá Cra 45, Colombia; caosoriora@unal.edu.co \\ 6 Département Génie de l'Environnement et des Organisations, Institut Henri Fayol, Ecole des Mines de \\ Saint-Etienne, 42000 Saint-Etienne, France; piatyszek@emse.fr \\ * Correspondence: gonzalezfeliuj@excelia-group.com
}

Received: 11 April 2020; Accepted: 25 May 2020; Published: 27 May 2020

\begin{abstract}
This paper provides a framework to analyze the maturity of humanitarian logistics systems to face crisis situations related to recurrent events, and thus to identify the main areas of action and the community needs in terms of crisis logistics planning. First, the main notions of humanitarian logistics systems planning, and the theoretical contribution of maturity models are presented. Second, a maturity model for humanitarian logistics systems is proposed and the main categories of elements defining maturity extracted from literature. Then, the methodology to define the main elements of the maturity model via evidence is presented. This methodology combines a literature overview, a documentary analysis, and the development of three case studies, two located in Colombia and one in Peru. The main elements that characterize capability maturity model in humanitarian logistics systems facing recurrent crises are identified, from which the administration of donations, design of a distribution network, and the choice of suppliers are highlighted. The practical implications of the framework are proposed to allow its use to anticipate humanitarian logistics system for future crises. The framework allowed a first analysis guide and will be further extended.
\end{abstract}

Keywords: humanitarian logistics; maturity model; recurrent crises

\section{Introduction}

Humanitarian logistics is a research and practice field whose main goals reducing the impact of natural or anthropogenic crises by deploying reactive and resilient logistics systems as a response. Natural crises (floods, eruptions, earthquakes, droughts, etc.) are increasingly numerous, as are anthropogenic ones (economic crisis, wars, terrorism, epidemics, explosions, etc.). This increase is largely due to climate change, wars over scarce resources, and socio-economic crises caused by poor political administrations of the territories, among others (Peres et al. 2012). The progress made in humanitarian logistics has made it possible to significantly reduce the number of deaths in the event of a disaster, although this reduction is still not enough (Fatemi et al. 2020). 
The life cycle of a disaster is usually understood, as proposed by Alexander (2002), as comprising four phases through which any type of crisis can be analyzed: mitigation, preparedness, response, and recovery. The literature on crisis management and humanitarian logistics has advanced by taking these phases into account, so any study to be proposed must respect this order to situate its contribution (Gonzalez-Feliu et al. 2019). However, recurrent crises seem to have received less attention in the literature, at least in a specific way, although its analysis can have a strong impact on anticipating future actions (Vargas-Florez et al. 2013). Indeed, while natural or not anthropogenic disaster is predictable, recurrent crises tend to affect a locality on a constant basis (Piatyszek et al. 2017; Vargas-Florez 2017; Choo et al. 2020; Xu et al. 2020). An example of this is the case of the El Niño phenomenon in Peru, which causes yearly flooding in the northern areas of the country (UN OCHA 2016). These locations affected by recurrent disasters require the development of a continuous response configuration and building resilience through long-term improvements of the humanitarian supply chain. Another example includes several areas in Mexico, Central, and South America that have been populated 'informally', with high population density and rising vulnerability to disasters (Klaufus and Van Lindert 2012; Salazar-Briones et al. 2020). In that context, and to support populations to increase resilience (and consequently to reduce vulnerability), it is important to have unified, transferable diagnoses and planning tools and methods (Gotham and Campanella 2013), focused on anticipating actions to face future disasters of recurrent nature. To support them, examining the notion of maturity (of humanitarian logistics systems to face such crises, (Lauras 2018)) can strengthen those unification and systematization goals, since maturity models are already systematized in other fields, including purchasing and logistics management (Potage 2017; Battista and Schiraldi 2013; Mallek-Daclin et al. 2017). However, and although several authors address humanitarian logistics maturity, measurements are made on an "own experience" basis without an aim of systematic unification. For those reasons, a systematic definition and characterization of humanitarian logistics systems' capability maturity (as already done in other logistics and process-based fields) seems crucial to achieve such unification goals.

This paper proposes a systematic maturity model for humanitarian logistics systems facing recurrent crises that considers the response systems and humanitarian supply chains, starting from a proposal of the maturity configuration from past works in different research fields (applied then to the specificities of humanitarian logistics to face recurrent crises)then identifying the main characteristics of such maturity via three case studies corresponding to the humanitarian response to flood crises in three territories: Salgar, Antioquia (Colombia), Arauca (Colombia), and Chosica, Lima (Peru). The maturity model contributes to the humanitarian logistics research and practitioner communities in the following ways: First, the proposed model is pre-defined from the common aspects of maturity models in a wide set of related fields, from human resource management to commercial and urban logistics, including healthcare, information system, purchasing and process management, among others. Second, the maturity model is then refined and the maturity characteristics identified via a field empirical data gathered from three case studies (constructed via a rigorous methodology of case building) reporting the logistics response to recurrent disasters; and third, the maturity model generates evidence that can be useful for reducing the cooperation distance between practitioners and academics. Thus, maturity characterization can be improved iteratively to fit the data successfully and relevantly.

The paper is organized as follows. First, a literature overview regarding maturity models and humanitarian logistics is presented, and a first proposal of the maturity model and the main categories of elements to analyze are given. Then, the methodological framework section proposes the case study definition and analysis methodology and the main data collection issues. After that, the results section proposes three case studies from which the maturity model is defined, and the main elements characterized. Finally, main findings and lessons are presented, as well as generalization issues and implications for both research (in terms of future work) and practice (communities' appropriation of such models). 


\section{Literature Review}

Maturity models were initially introduced in the field of psychology (Piaget 1971) and later to software engineering (Paulk et al. 1993; Wendler 2012). Then, industrial engineering and business management adapted them to diagnose the organizational efficiency of a supply chain and manage the quality of the provision from a product or service. Thus, the literature refers to "organizational maturity" as the ability to maintain or develop a performance that ensures, over time, the persistent satisfaction of the stakeholders of that organization (Cheshmberah and Beheshtikia 2020).

Maturity assessment allows for the measurement of progress obtained from any type of supply chain optimization policy (Cheshmberah and Beheshtikia 2020). This measurement has the advantage of being able to be interpreted in terms of a maximum goal of "organizational maturity". According to De Bruin et al. (2005), researchers must consider the following steps when developing a maturity model: (1) Define the scope, (2) design the model, (3) populate, (4) test, (5) deploy, and (6) maintain. In this work, steps 1-4 will be discussed and presented. Steps 1, 2, and 3 are presented in the Literature Review section and step 4 is discussed in the Results and Discussion section. Step 5 can be followed in the practice, then in future research, one might be interested in returning to steps $1,2,3$, and 4 to keep improving the model to fit the data.

Although maturity models are wide deployed in various fields (see next section), the theoretical contribution of maturity models in the field of humanitarian logistics remains mainly conceptual, and the practical, evaluation-based issues of such models are still at an initial level when concerning emergency, humanitarian, and relief logistics. Indeed, although various works address the notion of maturity dealing with humanitarian actions (Charles et al. 2010; Overstreet et al. 2011; Leiras et al. 2014; Laguna-Salvadó et al. 2015; L'Hermitte et al. 2018; Griffith et al. 2019; Gonzalez-Feliu et al. 2019), the notion remains qualitative, conceptual, and mainly unmeasured. However, some common facts and notions are seen in the literature. Firstly, the disaster life cycle as proposed by Alexander (2002) is a common guide for characterizing and analyzing the logistics systems in relief contexts (Overstreet et al. 2011; Holguín-Veras et al. 2012; Leiras et al. 2014; Vargas-Florez 2017; Gonzalez-Feliu et al. 2019). However, research in humanitarian logistics remains mainly related to operational phases and less on strategic issues, which leads to not considering the entire cycle in the proposed methods and results, but focusing on the reaction phase (Overstreet et al. 2011; Kunz and Reiner 2012). Indeed, Overstreet et al. (2011) acknowledge that research in humanitarian logistics has focused on the planning phase of disaster response, with less development in the other three equally important phases: risk mitigation, pre-disaster preparedness, and post-disaster recovery. The study of disaster response planning answers the following questions: What is the best strategy for distributing aid? How is humanitarian aid delivered in an optimal way? Post-disaster recovery includes all actions in continuity to response that lead to the restauration of a "normality" and start the reconstruction of disrupted systems (Holguín-Veras et al. 2014). Finally, the mitigation phase is defined as the one in which the risks of disasters are reduced, when they have not yet occurred (unlike the preparedness phase, it seeks to establish policies to mitigate risk before analyzing how to respond to a disaster).

The maturity of disaster response systems would be able to indicate if the local humanitarian supply chain is ready for reduce the impact of recurrent crisis. On the other hand, literature on humanitarian logistics is still insufficient, especially for those studies that do not address immediate disaster response (Leiras et al. 2014). Indeed, most scientific works in humanitarian logistics in relief focus on the disaster response, mainly at theoretical, modelling, and computational levels (Kovács and Spens 2007), although in recent years, the deployment of field-based and action-research works have led to a more practice-related viewpoint of humanitarian logistics research (Bai et al. 2019; Salam and Khan 2020). Moreover, it is also recognized that humanitarian logistics research approaches that integrate both theory and practice remain seldom deployed thereafter (Leiras et al. 2014). To cover this gap, maturity models attempt to draw a closer relationship between academia and practitioners by generating useful evidence for the stakeholders. (Altay and Green 2006; Natarajarathinam et al. 2009; and Kunz and Reiner 2012). 
Although organizational (Comfort et al. 2009; Liyuan and Qingmei 2014; Wu et al. 2013) and optimization (Banomyong et al. 2019) issues, mainly relying on either theoretical or case studies' data, continue dominating humanitarian logistics research (Kunz and Reiner 2012), measuring the performance and efficiency of humanitarian logistics systems has recently been a subject of interest, mainly in seeking the act of bringing theory to practice (Lauras 2018).

A first attempt of maturity quantification is seen in Charles et al. (2010) who propose a five-criteria measurement model based on capability maturity model (CMM) data collection framework. The chosen criteria are flexibility, velocity, reactivity, visibility, and effectiveness. The scales of measure (1 to 5) follow the CMM framework and the model is calibrated using the CMM data collection methodology in the case of IFRC's relief chain during its response to the 2006 Yogyakarta earthquake. However, the elements to measure inside each criterion rely on a top-down (deductive) measurement grid based on declarative scores. The grid proposed by the authors has not made the object of a cross-field validation. Other measurements, related to the capabilities of being efficient, resilient, or sustainable (and sometimes related indirectly to maturity) are also seen in the literature (Balcik et al. 2009; Overstreet et al. 2011; Leiras et al. 2014; Laguna-Salvadó et al. 2015; Gonzalez-Feliu et al. 2019). However, the deployment of an explicit capability maturity vision of humanitarian and emergency logistics remains relatively recent (Lauras 2018) and relies on the application of existing models without exploring the elements and factors that can influence maturity in humanitarian logistics. However, as shown by Charles et al. (2010), Holguín-Veras et al. (2012), and Gonzalez-Feliu et al. (2019), humanitarian logistics, in its different declinations, has particularities that merit the deployment of specific methods, going beyond a simple application of commercial logistics tools frameworks and tools.

In that context, the incorporation of systematic, measurable maturity models into the field of humanitarian logistics contributes to the literature of the disaster preparedness phase, providing a diagnosis of the 'organizational maturity' with which aid is provided in a locality. Since humanitarian logistics has specificities that characterize and distinguish it from other logistics and supply field sectors, it seems important to analyze and define such models from field data to define the main elements that compose the maturity of humanitarian logistics systems. L'Hermitte et al. (2018) uses a mixed-methodology approach to measure maturity in terms of response to a survey conducted on the key actors of the humanitarian supply chain for a community. Instead of building its maturity configuration from literature review, the authors opted for conducting a survey and define statistical measures as a maturity test. In fact, empirical knowledge was collected via survey method to overcome the scarcity of maturity configurations in humanitarian logistics field. Gutiérrez et al. (2019) define logistics capabilities which may affect the maturity level of the Home Health Care (HHC) provision. This maturity levels affect service quality, which is important to have a good response for the health system provided at home level. In most of recurrent disasters, HHC is important to advert epidemics of diseases caused by floods like: Dengue, chikungunya, cholera, etc. (UN OCHA 2016). This maturity configuration intends to build up on humanitarian logistics objectives, pursuing the minimization of deprivation costs after a disaster. Some other logistic elements of humanitarian supply chains remain nowadays unexplored as shown by the literature works presented above.

The literature in maturity models regarding disasters, humanitarian and/or emergency logistics remains scarce, and propose top-down adaptations of capability maturity models where field data are used to rank or grade maturity but not to characterize it (characterization is extrapolated from general maturity frameworks, without considering the specificities of crises, mainly in recurrent disasters contexts). What can be concluded from the review is that a different model is needed according to the different cases and sub-fields of research, but a general framework must be followed for building a maturity model (De Bruin et al. 2005). A goal and the capability to reach it cannot be measured without defining and characterizing standard criteria that define and grade this goal on a general maturity scale. As seen above, although efficiency (and then maturity) scales can be defined for humanitarian logistics systems, how the grades are attributed and, more importantly, on the basis of which elements (which need to be observable and transferrable, Gonzalez-Feliu 2018) are still unexplored subjects in 
humanitarian logistics. To define those elements and criteria, in line with the recommendations given in Gonzalez-Feliu (2018), this study will provide a qualitative diagnosis and a measurement of maturity. This methodology meets the research needs for the humanitarian logistics field (Overstreet et al. 2011; Leiras et al. 2014; Banomyong et al. 2019) and generates evidence useful to make a considerable impact on the efficiency of humanitarian operations.

\section{Constructing a Maturity Capability Model for Humanitarian Logistics Facing Recurrent Crisis}

In the field of humanitarian logistics, practitioners aim to save the maximum number of lives and alleviate human suffering. Research is not always aligned with the problem of cooperation in humanitarian logistics (L'Hermitte et al. 2018). Thus, a maturity configuration may intensify the cooperation between practitioners and researchers by generating analytical tools and empirical knowledge (Dijkzeul et al. 2013). According to De Bruin et al. (2005), maturity models can be either descriptive, prescriptive, or comparative. Descriptive models intend to capture the there-and-now situation of the supply chain system. Prescriptive models have the objective of purposing measures to reach higher level of maturities. Finally, comparative models pursue the ability of the model to generate a rigorous comparison between cases by benchmarking across organizations. The maturity model proposed here needs to address all three types: It should be first descriptive, since only description will allow the defining of the characteristics of a logistics system's maturity facing recurrent crises; it should, in the second place, feed evaluation approaches, therefore becoming prescriptive; finally, in an aim of unification, it should include comparability issues. So, although in this work the main contribution will be related to the descriptive version of the model, the proposed model will take into account the prescriptive use it will have (mainly for diagnosis of current humanitarian logistics systems) and finally allow for comparison of different cases (comparative use).

Maturity models have been associated with process capabilities, mainly in the software sector, from which a standard grid of lecture for Capability Maturity Models can be defined (Paulk et al. 1993; CP Team 2002). Indeed, most CMM are organized on five gradual levels, for which a series of common characteristics are observed, either for software (Paulk et al. 1993; Herbsleb et al. 1997), procurement and supply management (Potage 2017), project management (Kerzner 2002; Crawford 2014; CP Team 2002), business and process management (Rosemann and de Bruin 2005; Curtis et al. 2009; Lee and Kwak 2012), global logistics and supply chain management (Battista and Schiraldi 2013; Ruel 2019; Facchini et al. 2019), urban logistics (Morana 2015), or healthcare logistics (Mallek-Daclin et al. 2017; Gutiérrez et al. 2019). Moreover, efficiency measures in humanitarian logistics are derived from CMM models, although the explicit capability issues of maturity are not deployed (Charles et al. 2010; Varella and Gonçalves 2016; Laguna-Salvadó et al. 2019; Griffith et al. 2019). Table 1 shows the maturity models stage proposed based on literature. 
Table 1. Maturity model levels and common characteristics among the different research fields (authors' elaboration from synthesis of references cited above).

\begin{tabular}{|c|c|c|}
\hline Level & Characteristics & Key Elements to Consider \\
\hline \multirow{2}{*}{$\begin{array}{c}5 \\
\text { Advocating/Transforming/Capitalized/Optimized }\end{array}$} & $\begin{array}{l}\text { Continuous improving policies } \\
\text { linked to quantitative evaluation }\end{array}$ & \multirow{7}{*}{$\begin{array}{ll}\text { - } & \text { Practices } \\
\text { - } & \text { Processes } \\
\text { - } & \text { Tools } \\
\text { - } & \text { Stakeholders and } \\
\text { - } & \text { their relationships } \\
\text { Physical flow } \\
\text { management issues } \\
\text { - Information flow } \\
\text { management issues }\end{array}$} \\
\hline & $\begin{array}{l}\text { The entire organization is sensible } \\
\text { to continuous improvement }\end{array}$ & \\
\hline $\begin{array}{c}4 \\
\text { Sustained/Deployed/Managed/Measured and Qualified }\end{array}$ & $\begin{array}{l}\text { Processes are understandable and } \\
\text { measurable }\end{array}$ & \\
\hline $\begin{array}{c}3 \\
\text { Complied/Practicing/CompetencesDefined/Systematized }\end{array}$ & $\begin{array}{l}\text { Processes are unified and } \\
\text { improvements (gaps) are } \\
\text { measurable }\end{array}$ & \\
\hline $\begin{array}{c}2 \\
\text { Developing/Focusing/Disciplined/Repeatable/Acting } \\
\text { Stage }\end{array}$ & $\begin{array}{l}\text { The system's performance is } \\
\text { reproducible if the processes are } \\
\text { the same }\end{array}$ & \\
\hline \multirow[t]{2}{*}{$\begin{array}{c}1 \\
\text { Getting Started/Awareness Stage/Initial Level }\end{array}$} & Few sub-processes defined & \\
\hline & $\begin{array}{l}\text { The system's performance is } \\
\text { specific to context and not } \\
\text { reproducible }\end{array}$ & \\
\hline
\end{tabular}

One must consider the following key logistic elements to observe the general case, adapted from Potage (1998) and Morana (2015), maturity framework for urban logistics: practices (Potage 1998, 2017; Battista and Schiraldi 2013; Laguna-Salvadó et al. 2015; Morana 2015; Varella and Gonçalves 2016), processes (Paulk et al. 1993; Potage 1998; Rosemann and de Bruin 2005; Balcik et al. 2009; Curtis et al. 2009; Lee and Kwak 2012; Mallek-Daclin et al. 2017; Lauras 2018; Gutiérrez et al. 2019; Ruel 2019), tools (Potage 1998, 2017; CP Team 2002), stakeholders (Balcik et al. 2009; Potage 2017; Morana 2015) and their relationships (Varella and Gonçalves 2016; Griffith et al. 2019), and information flow management issues(Paulk et al. 1993; Herbsleb et al. 1997; Curtis et al. 2009; Lee and Kwak 2012; Ruel 2019).To that, since logistics systems and supply chains rely on physical, information, task, and decision flows (Lambert and Cooper 2000), we add an analogous category of element, physical flow management, which can also be defined as englobing product and material flow issues (Balcik et al. 2009; Charles et al. 2010; Battista and Schiraldi 2013; Morana 2015; Ruel 2019), task and decision elements (Potage 2017; Morana 2015; Varella and Gonçalves 2016; Laguna-Salvadó et al. 2019; Gutiérrez et al. 2019).Considering this general maturity configuration for urban logistics, a "zero-to-five" maturity model for the life cycle of recurrent crises is proposed (Figure 1).

Consequently, when defining a maturity model for humanitarian logistics, the main focus of the work needs to be first on defining and second on characterizing the domains of observation and expertise, on the basis of the macro-categories shown in Table 1: Practices, processes, tools, stakeholders (including the interactions among them) and information flows. When transferring them to humanitarian logistics, it seems important to take into account the following logistics functions (Balcik et al. 2009), which take into account practices, processes, stakeholders, and their interactions: Supplier choice, donator management, distribution network design, material convergence platform management (in pre-crises), material convergence management (in emergency situations), product assignment to beneficiaries, final distribution management, and local distribution network design (during emergency). However, those functions need to integrate all the life cycle of crises, for which some aspects are not directly concerned by the structure of Balcik et al. (2009). Indeed, authors consider a part of preparation (mainly in the definition of the distribution network design and pre-crisis material convergence management) and the emergency phases, but the recovery and mitigation are less evident. Recovery and mitigation can be related to different logistics aspects, from which only those related to humanitarian logistics facing crises will be considered (Brzoska 2019). Finally, the preparation and education of populations to react to future crises in a way to both reduce the eventual impacts on population and support the efficiency of the emergency logistics system can also be included. 


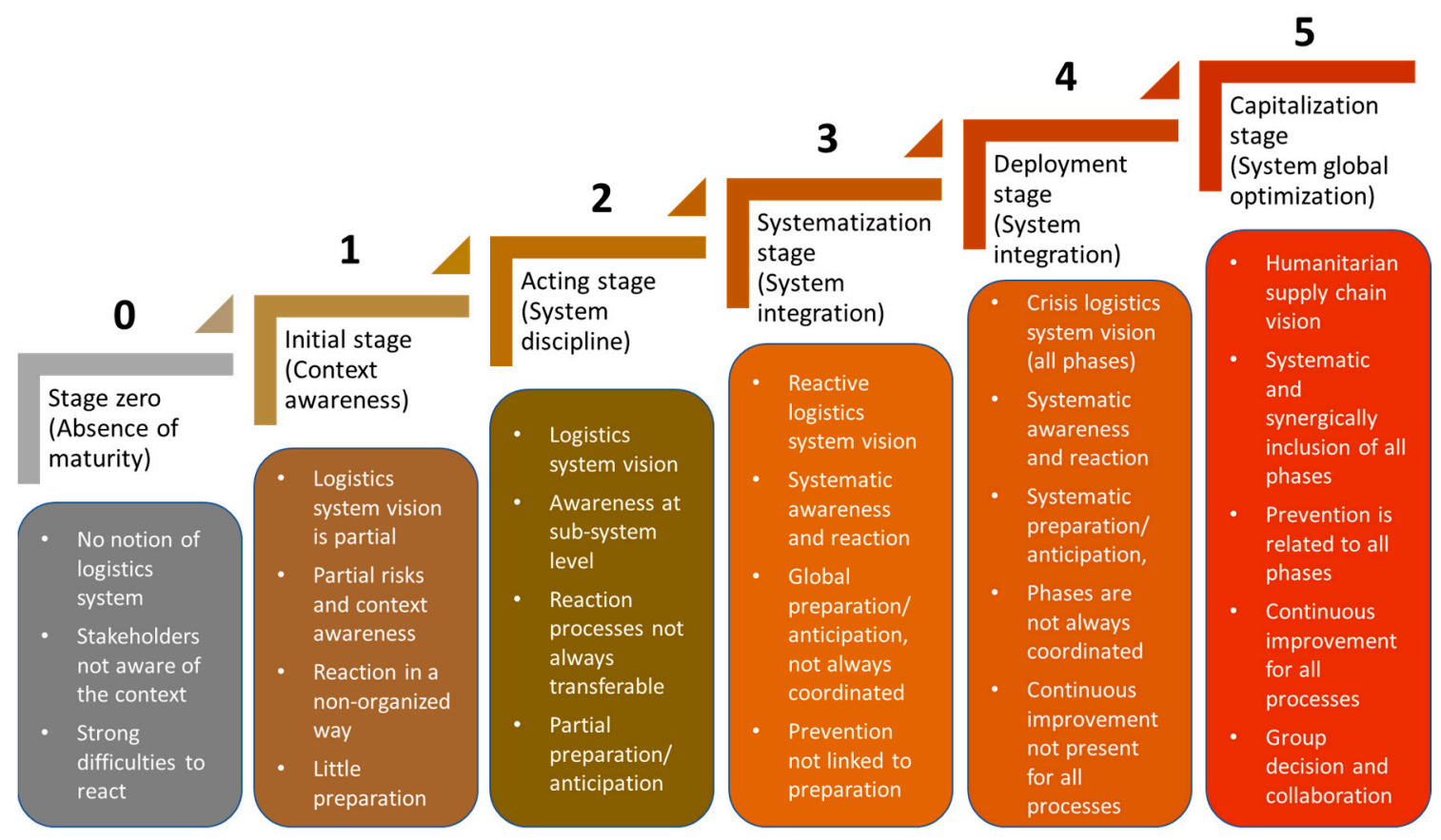

Figure 1. Proposal of a maturity model in the life cycle of recurrent crises.

In conclusion, to comment on that maturity, the phases of the crisis need to be considered (i.e., mitigation, preparation, response, and recovery (Alexander 2002)), as well as the main processes, in a narrow link to stakeholders and information flows. Consequently, the remaining of the paper will be mainly related to the identification of such processes as well as their characterization according to the specificities of humanitarian logistics to react to recurrent crises.

\section{Methodological Framework}

To examine the elements that define and orient capability maturity of humanitarian logistics systems, a case study approach was selected. The case study has been the object of various seminal works (Eisenhardt 1989; Yin 2018; Gammelgaard 2017), and recently, considering the fact that case studies are a popular way of characterizing and studying humanitarian logistics, Vega (2018) defined guidelines and methods to develop humanitarian logistics research-based case studies. Therefore, we present here the proposed methodology, based on the following structure (Yin 2018; Gammelgaard 2017):

1. Aim of the case study: The aim of the case study is to characterize and comment on the elements that define the capability maturity of humanitarian logistics systems. Taking into account this aim, the main issue of the case study is not to tell a "success story" or to retrieve information via storytelling, but to define, in a unified and transferable way, a set of criteria that define maturity on a set of cases then proposing to generalize them.

2. Nature, methodological path, and type of case study: From the aim and the literature review section, it appears that the case study proposed here cannot be either purely inductive (Eisenhardt 1989) nor purely deductive (Bitektine 2008). Indeed, to identify the composition of a maturity model, a comparative literature review and a first proposal of a model is made on deductive logic (so pure induction is not possible after that), and the conclusion of that first analysis is that humanitarian logistics systems need to consider their specificities when defining maturity, so pure deduction is neither suitable. For that reason, an abductive case study ${ }^{1}$ is

1 Abductive case studies combine induction and deduction in a synergic way, either by a reduction of the representation possibilities via induction then testing the retained ones via deduction, or by a deductive pre-identification of categories 
proposed, starting by the pre-selection of categories to examine (as presented and explained in Section 2) then a semi-directed data collection based on field feedback is carried out to identify such elements without having a very restrictive canvas to ensure local induction processes. Moreover, dealing with humanitarian logistics (Vega 2018), case studies cannot be made only on secondary information nor on pure observation/afterward interviews: It is necessary (since that is the nature of humanitarian logistics) to be in first person during the crisis to retrieve essential information about the particularities of the field (Holguín-Veras et al. 2012). To ensure a high degree of objectivity, the case study will not be a pure action-research one, but will need observation during the crisis response period, which implies that, in some cases, the researchers stop temporarily observation to contribute to helping the population (Osorio-Ramirez 2017), but this double experience (observation and action) leads to a better understanding of the case.

3. Number and selection criteria of the case study/studies: The maturity definition assessment needs to be made not on one but on various cases, from real situations, since the resulting model needs to allow its evolution into a prescriptive (quantitative evaluation) and a comparative tool (to compare different situations). Moreover, and since it was needed to deploy observations during a crisis, the main selection criterion of the cases was that of having a crisis of observable magnitude during the study period (2015-2017). A second criterion, to ensure homogeneity, was that the region and the type of crisis were similar and then considered as being of the same type. Pre-andine regions (mainly Peru and Colombia) were selected for proximity reasons, since most researchers are located either within or close to those areas. Moreover, since the most recurrent crises in the pre-andine regions are of flood nature, and the causes of them are homogeneous within the region, floods were selected as the type of crises to be observed. During the period, five crises were observed as potentially interesting, three in Colombia and two in Peru (including observation campaigns), but only in three of them was it possible to obtain both field observations and a relevant number of interviews: Two in Colombia (Salgar and Arauca) in 2015 and a flood in Peru (Chosica, Lima) in 2017. Those three cases were finally selected.

4. Data collection methods: To catch the needed information and allow both deduction and induction (which is necessary to deploy a synergic abductive approach), a mixed data collection method is proposed. Starting by a documentary analysis of reports, laws, and documents established to prepare the crisis, newspapers and other media information concerning the deployment of response to the crisis, and other technical documents of the involved stakeholders, a set of stakeholders located at each crisis place were defined and an observation protocol was established. That protocol defined 3-5 days of observation in which 1 to 3 researchers travelled to the crisis locations and followed the operations at different points and for different stakeholders, sometimes having to contribute to the relief operations. At each visit, a set of interviews on key stakeholders to be interviewed face-to-face was defined (based on the protocol of Gonzalez-Feliu and Morana 2010). Interviews were of non-directive nature but followed an aim of humanitarian supply chain characterization (processes, practices, stakeholders, and physical/information flows) from the conceptual model of Balcik et al. (2009). The details on the data collection phase are presented below.

5. Epistemological issues: The case study is inductive and is based on a mixed analytical-interpretative research. Indeed, pure qualitative methods are used, but are not the only ones: Analytical, text analysis, and problem structuring methods are used to retrieve information and complete the maturity definition criteria. The case study proposed here is then not a pure storytelling issue (as in (Gammelgaard 2017)) but a categorization/classification one

then an inductive identification of precise elements. In the present work, the literature review allowed for the definition of a set of categories that define maturity via deduction, but without defining specific elements; then, an semi-inductive case study data collection allowed, via a combination of induction and deductive comparison to literature, for defining the specific elements that define the maturity of humanitarian logistics systems in recurrent crises. 
(Gonzalez-Feliu and Morana 2010). Moreover, the information is retrieved in a socio-constructive way, as in Morana and Gonzalez-Feliu (2015). Indeed, collaboration among stakeholders but also researchers was needed to produce the required information and process it to deal with this research's goals.

The proposed methodology for the research is articulated in four phases, defined as follows:

- $\quad$ Phase 1: Context, background, and first maturity model definition;

- $\quad$ Phase 2: Case study data production and preparation of selected cases;

- $\quad$ Phase 3: Case redaction, synthesis, and analysis of joint information;

- Phase 4: Definition of the final maturity model for humanitarian logistics systems, discussion, and generalization of case results.

Figure 2 summarizes the full methodological procedure for the maturity assessment. We detail, in the following subsections, the main methodological issues of phases 1 and 2 .

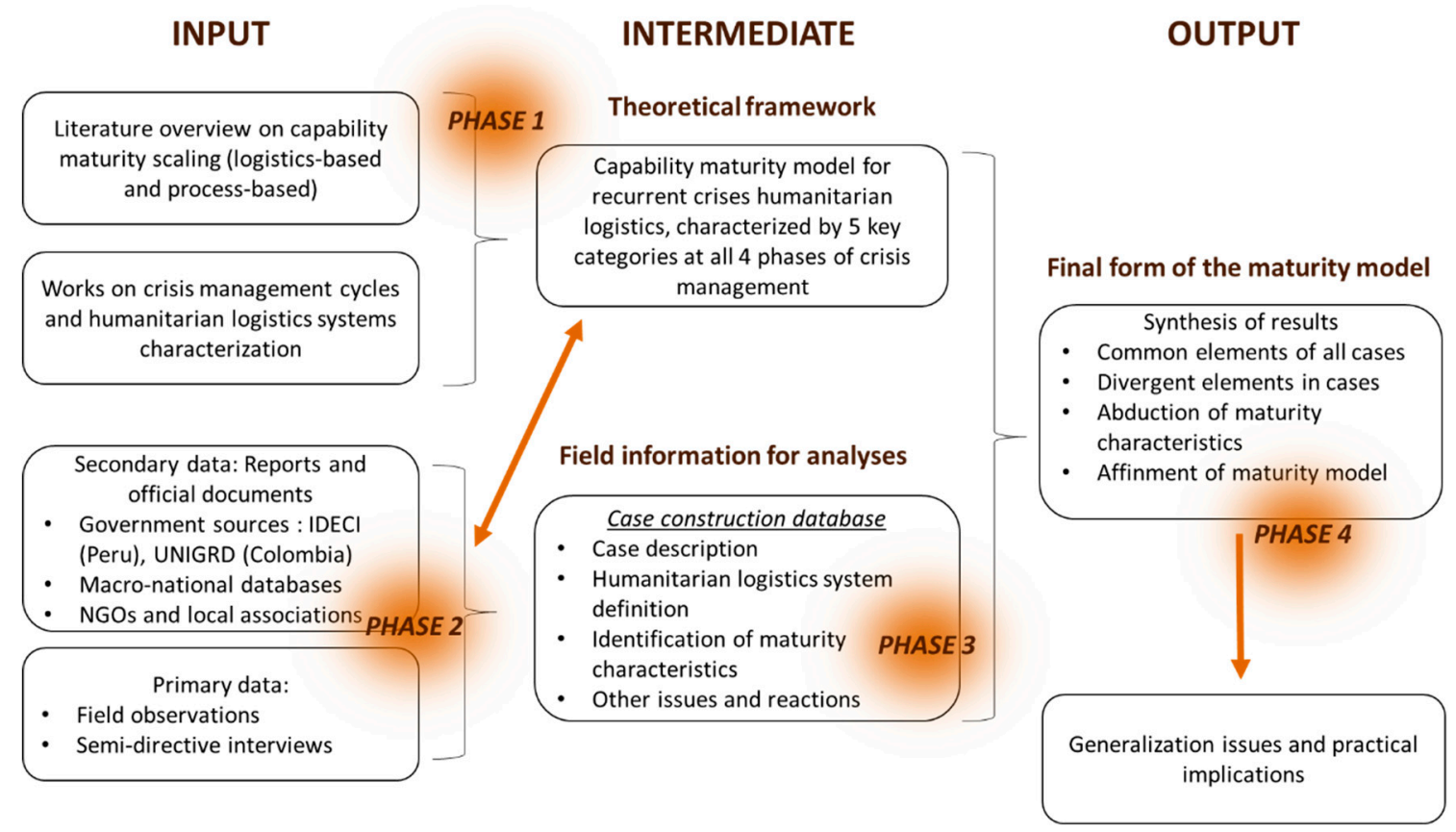

Figure 2. Methodological procedure for maturity assessment.

\subsection{Phase 1: Context, Background, and First Maturity Model Definition}

The first phase of the research consisted of analyzing both the existing literature on humanitarian logistics and on capability maturity model (CMM) definition and characterization. To do that, a set of core papers (most cited literature reviews) on the subject, as well as recent works (mainly of position/literature review nature), was selected and then completed by other essential elements. The main purpose of the literature overview was to set the context, position our research, and define the main scope of the following steps of the research, so a descriptive literature review was selected as the most suitable approach. Since few works of humanitarian logistics maturity were found, but the notion of maturity model has been widely studied in literature, the theoretical and methodological background to maturity model building has been constructed from examining common issues among maturity models in different fields (most of them directly or indirectly related to logistics and/or collaborative decision making) in order to define a first canvas of maturity model. The essential results of this phase have already been presented in Section 2, but this phase is, of course, an essential part of the integrated research methodology protocol. As already said, the main issue concerning maturity in humanitarian logistics that, to us, seems crucial to investigate at the current stage of the research in the 
field is that of finding a set of criteria and elements that characterize maturity and that can be used to define and compare cases and then, as a next step (out of our research scope), define standard measures of maturity. However, without a unified definition of maturity composition criteria, it is impossible to deploy measurable and comparable methods of maturity evaluation able to be deployed to different cases and allowing to compare them. For that reason, from Table 1 and Figure 1, as a conclusion of that phase, a set of categories to examine from field data are defined:

- Phases of the crisis, which are four, according to Alexander (2002): Mitigation, preparation, response, and recovery, as explained in Section 2.

- Tools, mainly related to information systems and traceability (Gonzalez-Feliu and Morana 2011).

- Stakeholders, specific to the context of humanitarian logistics facing crises (Holguín-Veras et al. 2012; Gonzalez-Feliu et al. 2019).

- Logistics processes and tasks, mainly related to sourcing and distribution (Balcik et al. 2009; Lauras 2018). We distinguish the following main processes in humanitarian logistics systems:

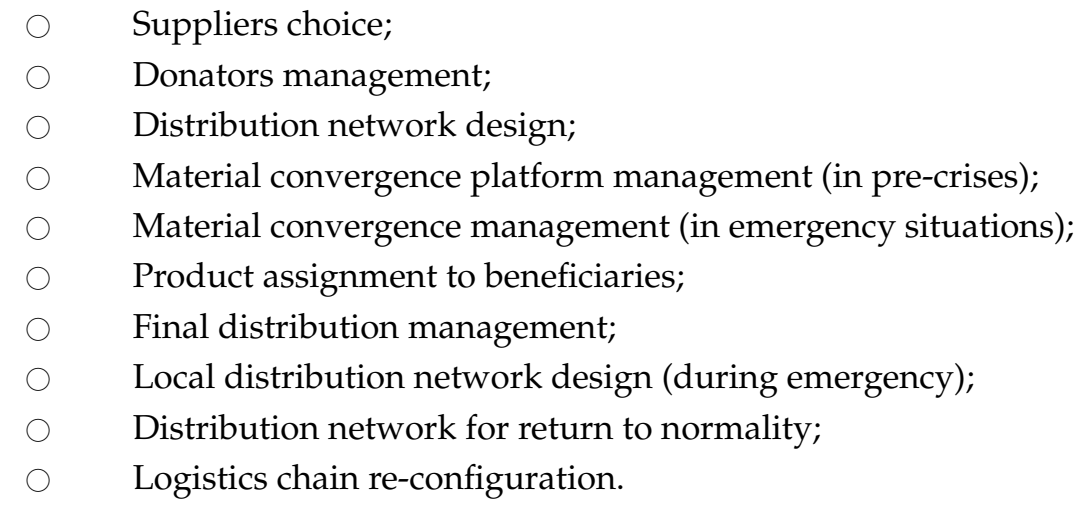

- Supporting processes and tasks (Gonzalez-Feliu and Morana 2011; Osorio-Ramirez 2017), in an analogous way than logistics process and tasks:

- Preparation and education;

- Coordination actions;

$\bigcirc \quad$ Information and communication flows and processes.

Those categories need to be investigated via observation and analysis of field data to define, for each of them, the main elements that characterize (and can measure) maturity in humanitarian logistics systems.

\subsection{Phase 2: Case Study Data Production and Preparation of Selected Cases}

As already explained, three cases were selected, due to opportunities and needs related to flood-based crises in the period in which research was done (mainly 2015 to 2017 for data collection), but also to the variety of information and the diversity of information retrieved. The first stage of the data collection, done in the early crisis reaction phase, consisted of retrieving relevant documents to characterize the case and find contacts for carrying out observations and interviews. Those documents mainly consisted of:

- Legislative and administrative documents (National government, Regional/local governance instances) regarding emergency planning and preparedness.

- Technical reports and documents from Non-Governmental Organizations (NGOs) and state and local Government and Administration Entities of operational nature.

- Syntheses of press releases and news concerning the events and the main reaction issues.

- Academic works on previous related events (at national level), mainly in national languages (Spanish) and of grey nature (Master Thesis, University reports). 
A first analysis of those documents allowed to define the main events, position the crises with respect to previous ones, and define an outline for visits and interviews. As an output of such analysis, a visit guide (for information retrieval) and a soft semi-structured interview guide (based on problem understanding and structuring, (Ackoff 1978)) were established. For each case, data collection was carried out during the end of the response phase and the beginning of the recovery phase (May to June of 2015 for the two Colombian case, March to June 2017 for the Peruvian one), combining a visit, several observations, and semi-structured interviews with representatives of different relief entities, public officials, and NGOs that participated in aid and response after the disaster (Osorio-Ramirez 2017). The interviews were mainly addressed to representatives of different relief entities, public officials, and NGOs that participated in aid and response after the disaster (the two Colombian cases were collected in the context of a PhD. Thesis (Osorio-Ramirez 2017), the Peruvian one followed the same methodology since the event occurred when the Thesis work was at a final stage). To this end, eight actors were interviewed in Salgar, six in Arauca (both in Colombia), and in Chosica (Lima, Peru). We detail the nature of interviews and the details of people interviewed in Table 2.

Table 2. Details of interviews for the retained three cases.

\begin{tabular}{|c|c|c|c|c|}
\hline Case & ID & Position & Institution & Date \\
\hline \multirow{8}{*}{ Salgar } & S1 & Volunteer & NGO & May 2015 \\
\hline & S2 & Regional manager & NGO & May 2015 \\
\hline & S3 & Technical employee & Municipality of Salgar & May 2015 \\
\hline & S4 & Technical employee & $\begin{array}{l}\text { National Unit of Disaster } \\
\text { Management (UNGRD) }\end{array}$ & May 2015 \\
\hline & S5 & Supervisor & $\begin{array}{l}\text { Regional Disaster Prevention } \\
\text { and Management (DAPARD) }\end{array}$ & May 2015 \\
\hline & S6 & Technical employee & $\begin{array}{l}\text { Regional Disaster Prevention } \\
\text { and Management (DAPARD) }\end{array}$ & May 2015 \\
\hline & S7 & Head of service & Civil Defense & May 2015 \\
\hline & S8 & Member & Firemen & May 2015 \\
\hline \multirow{6}{*}{ Arauca } & A1 & Member & Firemen & May 2015 \\
\hline & A2 & Volunteer & NGO & June 2015 \\
\hline & A3 & Technical employee & Municipality of Arauquita & June 2015 \\
\hline & A4 & Political leader & Community of Saravena & June 2015 \\
\hline & A5 & Volunteer & NGO & June 2015 \\
\hline & A6 & Political leader & Community of Arauquita & June 2015 \\
\hline \multirow{9}{*}{ Chosica } & $\mathrm{C} 1$ & Technical employee & Municipality of Lima & March 2017 \\
\hline & $\mathrm{C} 2$ & Head of logistics & National transport company & March 2017 \\
\hline & $\mathrm{C} 3$ & Manager & Local transport company & March 2017 \\
\hline & $\mathrm{C} 4$ & Local retailer & Community of Chosica & March 2017 \\
\hline & $\mathrm{C} 5$ & Employee & Local security unit-Chosica & April 2017 \\
\hline & C6 & Member & Civil Defense-Chosica & April 2017 \\
\hline & $\mathrm{C} 7$ & Head of logistics & National transport company & June 2017 \\
\hline & $\mathrm{C} 8$ & Project manager & $\begin{array}{l}\text { National Federation of } \\
\text { Engineers }\end{array}$ & June 2017 \\
\hline & C9 & CEO & Logistics consulting company & June 2017 \\
\hline
\end{tabular}


In parallel to those interviews, visits of the crisis locations were made, one to Arauca (May 2015) and one to Salgar region (June 2015), the first of two days and the second of five days. Concerning Chosica and considering that the location is in the same metropolitan area as two of the research teams involved in the research, six visits and data retrieval actions were made between March and June 2017.From all collected information, a report (in Spanish) was prepared describing the cases and the results of the interviews. Then, a joint analysis of the case characteristics and the main common elements that define maturity was made and is presented in the following section. The cases presented below will follow a structure on 5 blocks: brief presentation of the facts, elements of coordination, issues regarding preparedness and issues regarding response. Then, the main elements of maturity, according to the categories of key elements presented in Table 1 (practices, processes, tools, stakeholders and relationships, physical flow management, information flow management), and a systematic capability maturity model, unified and transferable, is proposed, including a set of specific elements to observe and identify when defining maturity of humanitarian logistics systems facing recurrent crises. Finally, generalization issues were also addressed and are presented at the end of the results section.

\section{Results and Discussion}

\subsection{Brief Presentation of the Case Studies}

\subsubsection{Mudslide—Salgar, Antioquia (Colombia)}

In 18 May 2015, a mudslide occurred because of the overflow of the La Liboriana stream, which affected the municipality of Salgar. The damages included: 93 people deceased, 11 missing persons, 1549 people and 462 families affected, 66 homes destroyed, 24 semi-destroyed and 219 affected, and 7 affected vehicular bridges and 1 destroyed.

The coordination: At the regional level, due to the implementation of the national disaster risk management policy, the DAPARD (Administrative Department of the System for the Prevention, Attention, and Recovery of Disasters of the Government of Antioquia) was created, which chairs the Departmental Management Council of Disaster Mitigation and is in charge of the Humanitarian Logistics Center. To decentralize risk management, DAPARD creates SIGERD (Integrated Disaster Risk Management System), through this platform, all those involved managed to go to the disaster area in Salgar with clearly defined tasks. There was decentralized aid supplied at regional level with predetermined task defined for every institution.

The disaster preparedness: At the regional level, the municipality of Salgar with the risk management plan had already identified the risk scenarios. Likewise, knowledge and risk reduction programs were contemplated, as well as disaster management. However, the regional government did not prioritize these programs or approve the budget. However, the fire department invested in new equipment and training. In addition, entities such as Corantioquia and Ingeominas warned that a plan to relocate the vulnerable population had not been considered. Early warning systems were a pending task for UNGRD, DAPARD, and Corantioquia, and the emergency response strategy had not been socialized. The DAPARD humanitarian logistics center had a pre-positioned inventory of humanitarian aid, but it was not enough when the Salgar disaster occurred because it was used to attend to other previous emergencies in other municipalities of the department.

The disaster response: The response was made in a series of stages, summarized as follows.

1. The previous night, DAPARD had issued an orange alert (high probability of rain in the area). The villagers communicated with each other by phone calls. DAPARD was present as soon as the emergency was notified and managed the resources and personnel for humanitarian assistance. The first to arrive were Civil Defense, The Red Cross, the firemen, and the National Police. Water services were suspended and a water tanker from a neighboring municipality was available. The next day there were already 25 tanker trucks while the energy and gas services were gradually restored. 
2. The delivery of humanitarian aid began towards the end of the first day and when it finished over $10 \%$ of water. Initially, the people who made the donations in the municipality made the distribution. Then, with the support of a local social organization, the donations were stored and distributed in the coliseum of the municipality with the support of seven volunteers who did not have any prior knowledge of inventory management, but were in charge of the reception, classification, control, and delivery of the donations. In addition, three volunteers were assigned to carry out the census of the affected population.

3. During the first two days after the disaster, there was great influx to receive humanitarian aid. The volunteers identified a problem because the delivery of the aid was made without prior verification that the person was injured, which caused unscrupulous people to benefit. By the second day after the mudslide, 212 humanitarian aid kits had been delivered by DAPARD and UNGRD. Likewise, it was identified that between $30 \%$ and $40 \%$ of the clothes received were in poor condition and were not suitable for donation. In addition, low-priority donations did not exceed $10 \%$ of the donations received. By the third day, 332 kits had already been delivered. However, the exact number of victims who were benefited with kits delivered in the municipality had not been identified.

Main relevant facts and discussion: The Red Cross, Civil Defense, Fire, Air Force, and Police demonstrated clarity in the scope and performance of their roles when deploying their capabilities to address the emergency. They also recognized the importance of the coordination role of UNGRD at the national level and DAPARD at the regional level. The role of DAPARD as coordinator at the territorial level is highlighted. This was the first successful case of the regional implementation of the risk management national policy (territorial entities must take on the tasks of coordinating risk management in their regions). Although there was a risk management plan with defined programs, they were not executed due to financial and political issues. The involvement of the local community in the disaster response strategy was a key factor. However, there was a lack of technical and operational capacity on the part of the municipality to execute the plans. The inclusion of the community in the risk management plans facilitates the improvement of the logistical capacities of disaster attention. The inventory policy of the kits may be subject to improvement.

\subsubsection{River Overflow-Arauca Region (Colombia)}

On 25 May 2015 and for several days, there were heavy rains in the municipalities of Saravena and Arauquita located in the department of Arauca, a situation that generated the overflow of the Arauca River and their tributaries. The damages included: 12,000 people affected, 2 deceased persons, 243 affected homes, 23 homes destroyed, 19 schools, 9 roads, 13 bridges, 3 aqueducts, and a community center affected, and $80 \%$ of the crops and production of the main agricultural products were recorded as lost.

The coordination: The municipal and departmental administration relies on the public forces and the armed forces. Likewise, the police and the army are fundamental for decision-making in the municipal risk management committees. In addition, there are acceptable communication levels between the forces and other organisms (Fire, Civil Defense, and NGOs).

The disaster preparedness: Despite not having a risk management plan, the 2012-2015 municipal development plan included disaster risk management as a critical component and identified areas of major risk and vulnerability due to floods. In addition, the development of programs designed to support the relief agencies had been proposed, which has strengthened the capabilities of the fire department. Despite the acquisition of new supplies and equipment, they were insufficient when dealing with emergencies. For their part, NGOs (mostly religious) promote disaster preparedness and risk management projects, in the same way these institutions also provide community health services.

The disaster response: 
1. Thanks to early warnings, the municipal council of risk management warned the city of Arauca of heavy rains, through local radios. These alerts immediately activated the crisis room of the municipal council of risk management in Saravena and on the second day of the river increasing levels, the mayor reported the declaration of public calamity.

2. The humanitarian aid and donations were arriving and consolidating in its majority in Arauquita, for being a municipality equidistant to the affected areas and with access by land. Although there was support for the handling and distribution of aid, the volume of donations was not significant enough to affirm that there was a problem of convergence of materials in relation to the storage and handling capacity of the aids. As a result, the UNGRD aid kits arrived directly at the affected municipalities. In Saravena, a storage area for kits and donations was available, which was administered by UNGRD. They used the same truck for transportation and storage.

3. The participation of the community and the NGOs facilitated the administration of the aid. By 1 June, UNGRD had delivered food kits, 1000 toilet kits, and 3000 mosquito nets and hoses in the municipalities of Saravena and Arauquita. However, some families located in areas of difficult access had not been counted for the delivery of humanitarian aid.

Main relevant facts and discussion: There is a determining role exercised by the military forces in the coordination of humanitarian operations. The disasters caused by the floods in the region have been considerable and the departmental government has not had sufficient resources to serve the affected population because of what the UNGRD supports to support these events. There is no risk management plan to enforce the national policy, which can have a negative impact when dealing with the affected people. Although the actors involved in humanitarian operations say that their roles are naturally well defined, the articulation of the community or humanitarian organizations in the risk management programs is not clear from the local development plans. The phenomenon of convergence of materials in the arrival of donations to the affected areas is interesting, since the volume of aid was not so high compared to other registered cases.

\subsubsection{Flood-Chosica, Lima, Peru}

On February to March 2017, a series of intense rains in the context of a Coastal Niño phenomenon touched Ecuador and Peru coastal areas. That event caused more than 100 deaths in Peru and isolated and devastated some important cities as Trujillo and Piura, also causing important damages in the Lima metropolitan area. Chosica is referred to as one of the most affected districts in Lima. Several areas were seriously affected after a series of floods that disabled housing, collapsing the walls and risking the lives of villagers who were not willing to leave their homes. Their houses ended up flooded with mud and undergrowth in the middle of the riverbed.

The coordination: In Peru, INDECI is in charge of providing the humanitarian aid goods when the Regional and Local governments exceed the response capacity, and the Damage Assessment and Needs Analysis must be found, being registered in the System of National information for the response and Rehabilitation. INDECI works with five levels of emergency impact emergency. The first levels are in charge of the district, provincial, and regional governments, who are the first to provide capacity before any danger, in case these governments exceed the capacity of response; the state of emergency is sustained, and they request support from INDECI. Levels 4 and 5 correspond to those levels of disaster impact that support the declaration of a state of emergency, affect the life of the nation, and exceed the capacity for response. Donations are made by individuals, legal entities, and NGOs. In El Niño Costero, the inventory was not enough, and assistance was received from NGOs and INDECI for overcoming the response capacity.

The disaster preparedness: INDECI, in its logistics plan for humanitarian aid in the event of an emergency or disaster, aims to maintain the appropriate stock levels of pre-positioned humanitarian aid goods in general and national warehouses. It has 20 stores nationwide, 3 of them located in Lima and 17 located in different cities of the country: Piura, San Martin, Amazonas, Loreto, La Libertad, Junin, Ica, Arequipa, Tacna, Juliaca, Puno, Cusco, Tumbes, Lambayeque, Huancavelica, Ucayali, 
and Pasco. In addition to INDECI, the country has four additional institutions for risk management and prevention: SINAGERD, which establishes a comprehensive and decentralized approach that includes prospective, corrective, and reactive disaster management; COEN, a reactive management instrument, which works continuously to monitor hazards, emergencies, and disasters, as well as manage timely information for making decisions at the national level; EDAN, which is a technical instrument, that by collecting data and processing qualitative and quantitative information allows one to know the damages that a community has suffered; and, finally, SINPAD, which allows obtaining timely information from all organizations in the face of a disaster.

The disaster response: Due to the occurrence of heavy rains, the government proposed complementary measures for immediate and necessary actions, to get a response and recovery, just as the declaration of a state of emergency for natural disasters. Consequences of the rains included overflowing rivers, collapses, and floods, damaging homes, public facilities, main, and access roads. These are measures to receive immediate help in the face of emergencies, through emergency decrees. Similarly, the government approves amending budgets to perform emergency activities and focus on key areas. In the case of Chosica, there was a request of immovability for the armed forces and the national police, to dedicate themselves to salvage work and disaster prevention. The government establishes different points for the collection of donations of different actors (citizens, NGOs, private entities) and subsequent distribution of the same. Two kits, one for adults and the other one for kids, were provided and they contained water, preserves, rice, cleaning supplies, games for children, as well as diapers. Lima's city hall, for their part, opened shelters for the affected people, and these had water, a generator, and healthcare. Due to the lack of water, the government provided water tanks. Lurigancho, Chosica's city hall, established and regulated the rules as well as the procedures for the acceptance, management, and distribution of donated and/or acquired humanitarian assets in case of emergency.

Main relevant facts and discussion: Disaster risk management policies seek to promote prevention in management, developing a culture of prevention and safety in the face of disasters, improving education for management, and guaranteeing restoration and resilience means to recover the economically and socially affected population. They also promote prevention for disaster risk management at the national level as well as awareness and development of resilience and resilience capacities in citizens for mitigation. The institutions responsible for responding to emergencies, in coordination and collaboration with private companies, must educate and prepare the community on how to act in case of emergencies, establishing a resilient and resilient system. The community needs to be informed and involved in disaster prevention management through the government via the use of information exchange platforms on disasters.

\subsection{Synthesis and Construction of the Maturity Model}

We propose here a synthesis of the results and their relation in the search of an identification of principles and elements of a Maturity model.

\section{Maturity Model Elements Definition and Discussion}

From the synthesis of the three presented cases, we can induce from the proposed cases the main elements to include into a maturity model dealing with humanitarian logistics in case of recurrent crises; the aim of this research not being to measure and evaluate maturity, but to understand the main elements that define and compose it. We present those elements in Table 3.

Concerning the sourcing process, in Colombia, UNGRD oversees humanitarian aid kits sourcing to their National Logistics Humanitarian Center, who have a defined minimum inventory. In the case of Antioquia, the Administrative Department for disaster prevention and recovery (DAPARD) is the entity who supervises the reception and distribution of such kits. In the case of Peru, INDECI manages providing humanitarian aid goods, in case the regional and local governments exceed responsiveness. Prior to delivery of donations, the damage assessment and needs analysis were done. They determine 
whether the area requires the intervention of INDECI. These kits are composed of the purchases by INDECI and the donations made by different entities. The three cities do not have previously identified providers specific to urban units (in Peru, a directory of providers exists as a national level but not related directly to Chosica); additionally, they have not established their management indicators. Nevertheless, the sourcing process is defined. Consequently, the main issues related to sourcing that appear in all cases are suppliers' choice and relief supplies prepositioning, which have analogies with the purchasing processes of maturity models (Potage 1998, 2017) but in humanitarian logistics rely on a wider set of stakeholders and their interactions. Those issues appear mainly in the preparation phase. Moreover, donator management, which cannot be anticipated and appears in the response phase, is also related to supply and sourcing processes, and remains one specificity of maturity capability in humanitarian logistics systems dealing with emergency and relief contexts. Donator management can then be extended to a mitigation phase (as shown in the three cases where learning led to the need of anticipating and preparing donations flows) for a more resilient then mature logistics system.

Table 3. The main logistics elements of the maturity model to respond to crisis (obtained inductively with evidence from the three selected cases; elaboration: Authors).

\begin{tabular}{|c|c|}
\hline Phases of the Crisis & Logistics Processes and Tasks \\
\hline \multirow{6}{*}{ Response } & $\begin{array}{l}\text { Donators' management: Selection of pertinent goods and management of } \\
\text { donators' uncertainty. }\end{array}$ \\
\hline & $\begin{array}{l}\text { Material convergence management (in emergency situations): Management } \\
\text { policies and processes at execution level (real time) }\end{array}$ \\
\hline & $\begin{array}{l}\text { Product assignment to beneficiaries: Real-time assignment and re-assignment } \\
\text { policies and processes }\end{array}$ \\
\hline & Final distribution management \\
\hline & Local distribution network design and management (during emergency) \\
\hline & Distribution network for return to normality \\
\hline \multirow{2}{*}{ Recovery } & $\begin{array}{l}\text { Distribution network restart or restauration: Support of humanitarian logistics to } \\
\text { the deployment of regular logistics and distribution services }\end{array}$ \\
\hline & $\begin{array}{l}\text { Distribution network design: Re-configuration and improvement of the } \\
\text { humanitarian distribution network at the reconstruction phase. }\end{array}$ \\
\hline \multirow[t]{2}{*}{ Mitigation } & $\begin{array}{l}\text { Operationally reaching: Restarted services attain an operational stage, and families } \\
\text { reaching a status with no post-crisis related needs (status quo nearly reached). }\end{array}$ \\
\hline & $\begin{array}{l}\text { Donators management: Reconfiguration and development of donators } \\
\text { management policies to anticipate future crises }\end{array}$ \\
\hline \multirow{4}{*}{ Preparation } & $\begin{array}{l}\text { Suppliers' choice: Selection of suppliers to prepare basic kits but also to react when } \\
\text { crisis arrives. }\end{array}$ \\
\hline & $\begin{array}{l}\text { Relief supplies pre-positioning: Define products or kits, inventories, locations and } \\
\text { capacities of emergency warehouses. }\end{array}$ \\
\hline & Preparation and education: Preparation to readiness for operational employees \\
\hline & $\begin{array}{l}\text { Preparation and education: Introduction of logistics-based approaches in general } \\
\text { education to crisis reaction }\end{array}$ \\
\hline
\end{tabular}

Regarding the distribution process, in the case of Colombia, the help that comes from UNGRD reaches a point that is located near or inside the affected area and it is defined by members of the national risks and disasters management system. The donations do not necessarily go by these points; they go directly to reception and distribution centers, where the UNGRD has almost zero interaction with donations. In the case of Arauca, humanitarian aid reached Arauquita, and it acted as a local point of the other city halls and the shipments made by UNGRD went directly to each city hall. The reception-distribution centers are defined according to the UNGRD event, which supervise 
the central warehouse. The donations were administered by other organizations; at first, they were distributed by the same donors, then the main local social organization intervened. and with local support, the management of donations was unified in Salgar's case. In Peru, the local warehouse is under the responsibility Chosica's city hall. The donations are loaned by private, public, and non-governmental organization entities, and its delivery is coordinated with the city hall; however, the centers of reception-distribution have not yet been defined in advance in accordance with the risks. Similarly, the means of transport have not been incorporated as part of the management module and key criteria reports have not been included, so that the prioritized delivery will not be considered subjective.

From the three cases, the main issues regarding the distribution process that seem to define maturity are related first to operational choices during the response phase (mainly management policies and processes at execution level in real time for material convergence, assignment issues of product beneficiaries to reduce suffering of victims, and all real-time issues related to final distribution management in a perturbed situation, including network design issues). Then, improvements of what was lived in cases would be done, at a mitigation phase, by deploying of a robust distribution network for return to normality and the re-configuration and improvement of the humanitarian distribution network at the reconstruction phase. Finally, at a preparedness phase, it seems crucial to reach operationality of the regular logistics services quickly, to reach families with no specific post-crisis related needs (i.e., where status quo is nearly reached).

Concerning traceability tools, in Colombia, at the beginning, humanitarian aid was provided to people who were not identified as affected. This allows us to conclude that there is not a well-defined managing system. The person who supervises the process, the traceability tools, or management indicators are also not defined. In the case of Peru, the local and regional government delivered the aid kits within five days of the disaster, with some delays due to late damage registration, tools for the humanitarian aid delivery only to the affected people, as well as an inventory of goods. The use of tools/process must be defined in advance and delivered to the affected people. Since the current acceptability and use of such tools remain preliminary, even for everyday operations, in the area, we did not propose any traceability-specific issue in the maturity model. The development of specific information system and traceability tools-oriented researches will allow the definition of a more in-depth insight in the question.

In terms of human resources and stakeholders' interactions, in the case of Colombia, the organism in charge of the actors' coordination for the attention of disasters is the city hall council; however, given the magnitude of the events' disaster, UNGRD and the Departmental Council and/or DAPARD participated. Naturally, the actors manifest their determined roles; notwithstanding, their participation is not clear in local plans. This denotes a lack of technical and operational capacity of the city hall to make these plans operational, as in Salgar's case. The plans were not shared with the community, nor trained for tasks that were carried out before an emergency (reception and inventory management of donations, knowledge on demand management).In Peru, local, regional, and national governments activate the process of response, depending on the emergency level and responsiveness, the intervention of other actors' increases, such as INDECI, ministries, public, and private organizations, as well as donations. There are no concrete contingency plans before disasters in city halls and regions; mainly, those who require the involvement of the community and its prior socialization. The roles between logistical management and negotiation of providers have not been clearly defined either, as well as making the processes independent with entities who have a good reputation in the population. Relating those issues to maturity, it seems important for humanitarian logistics systems to focus not only on human resources or internal stakeholders (as in classical logistics or urban logistics maturity models, Battista and Schiraldi 2013; Morana 2015; Ruel 2019), but focus on preparing populations to face the crisis, via preparation to readiness for operational employees or introduction of logistics-based approaches in general education to crisis reaction. 


\section{Conclusions}

This paper presents a framework to identify and analyze the maturity of humanitarian logistics facing crises. The main focus of the research is on the identification of the main key components that can be associated with the maturity of a logistics system facing a recurrent crisis. After an overview of humanitarian logistics and recurrent crises, the paper presented the main notions of maturity in logistics and a canvas to analyze the maturity of humanitarian logistics facing recurrent crises. Then, three cases were presented: Two in Colombia and one in Peru, with the fact that they dealt with floods in common. The results show that the three cases had common characteristics that allowed for the identification of the main elements defining the maturity of humanitarian logistics systems facing recurrent crises. However, it is emphasized that, since they do not have mastery of lean management, notions such as flexibility, continuous improvement, and reliability may seem easy to adapt to the humanitarian logistics that face crises. Anyway, each case seems to have a different maturity level, but the common points allowed for the understanding of the main components of maturity in the case of logistics systems to respond recurrent crises.

The proposed maturity model allows then a framework to analyze the responses to different emergency situations of recurrent climatic events, but does not mediate and/or assess the level of maturity. Although the results of this research aimed to identify the composition of maturity and not to provide an assessment framework, robust generalization will only be made after using the maturity model proposed here in a large set of cases and recurrently refining and validating it. In any case, the proposed model is a good, unified basis, which follows (by its theoretical and methodological construction) a standard procedure that is then able to be replicated; moreover, this type of tool can only be improved via research-action processes, so the contribution gives a tool for further research and practice actions. Moreover, the model would feed anticipation and forecasting methods (Lee et al. 2018; Salazar-Briones et al. 2020), both by qualifying the current situation and defining targets and needs for quantitative planning and assessment. However, since the first step was to define and characterize maturity, this work remains qualitative in nature and would be extended to relate each maturity category defined here to the most suitable indicators and methods to measure them. For those reasons, future research will aim to complete this framework towards the definition or an integrated methodology to quantitatively assess and evaluate the maturity and then give a value measurement dimension to maturity.

Finally, it is important to address the main practical implications of the proposed framework and results. First, the relationship between a systematic, unified vision of maturity and crisis management is seen at the diagnosis and assessment levels: The proposed model will allow organizations to have a unified vision of maturity, being able to propose comparable diagnosis and assessments and having a comparison basis, not only among crises, but (more importantly for recurrent crises), between two (or more) crisis of the same type in the same territory (for example, Chosica faced floods of different nature three times in the last 40 years). Although, nowadays, all information of past events will not always allow a quantitative characterization, the proposed framework can support a qualitative, grade-based assessment, and support the deployment of quantitative information retrieval methods to anticipate future crises in recurrent contexts. Second, having a categorization of maturity elements will allow for decomposing maturity in a set of criteria, and then deploying standard indicators, working towards the definition of humanitarian logistics Key Performance Indicators (KPI, as on other fields, for example urban logistics, where the specificities made a recent definition of standard KPI different from classical supply chain management ones, (Morana and Gonzalez-Feliu 2015)). Third, resilience and vulnerability indexes (Osorio-Ramirez 2017; Vargas-Florez 2017) would be completed with maturity ones, allowing international organizations to propose cross-country comparisons. Finally, in a collaborative, multi-stakeholder environment, maturity models will reinforce group decision making and continuous improvement, leading to more reactive and resilient systems. 
Author Contributions: Conceptualization, J.G.-F., M.C. and I.B.; methodology, J.G.-F., M.C. and C.O.-R.; data collection and processing, M.C., C.O.-R., I.d.B.J. and R.Q.A.; validation, J.G.-F., J.V.-F. and E.P.; investigation, J.G.-F, M.C., J.V.-F. and C.O.-R.; resources, M.C. and R.Q.A.; writing-original draft preparation, J.G.-F., M.G., J.V.-F. and E.P.; writing-review and editing, all authors; supervision, M.C., I.d.B.J.; project administration, J.G.-F., M.C.; funding acquisition, J.G.-F., M.C., C.O.-R. All authors have read and agreed to the published version of the manuscript.

Funding: This research was partially funded by the AURA Scusi 2019 project REFLEX as well as from the internal Research Funds of U. Pacifico, grant 2019. Two of the three presented cases were part of Carlos Osorio-Ramirez' $\mathrm{PhD}$. Thesis, directed by Wilson Adarme Jaimes and partially financed by Universidad Nacional de Colombia, sede Bogota, Grupo de Investigacion SEPRO. The APC were entirely covered by a waiver from the MDPI's Free Feature Paper Program for Previous Reviewers.

Acknowledgments: Authors aim to thank Gabriela Maravi and Rodrigo Rivadeneira, former research assistants at Universidad del Pacifico for their contributions to previous versions of this paper; Rebeca Mori, Karen Ramos, Melissa Rivas for their contributions and the field work in Chosica presented in their Ms. Thesis at Universidad del Pacifico, directed by M. Chong; as well as to Wilson Adarme Jaimes, Universidad Nacional de Colombia, for his advices and suggestions regarding the research. Authors thank also the three anonymous reviewers for their comments and recommendations that contributed to the paper's strengthening and improvement.

Conflicts of Interest: The authors declare no conflict of interest.

\section{References}

Ackoff, Russell Lincoln. 1978. The Art of Problem Solving: Accompanied by Ackoff's Fables. New York: Wiley.

Alexander, David E. 2002. Principles of Emergency Planning and Management. New York: Oxford University Press.

Altay, Nezih, and Walter G. Green III. 2006. OR/MS research in disaster operations management. European Journal of Operational Research 175: 475-93. [CrossRef]

Bai, G. Vidya, Daniel Frank, K. Satish, and Protichi Chatterjee. 2019. Humanitarian Logistics: A Key Factor in Disaster Management. International Journal of Management and Business Research 9: 28-34.

Balcik, Burcu, Benita M. Beamon, Caroline C. Krejci, Kyle M. Muramatsu, and Magaly Ramirez. 2009. Coordination in Humanitarian Relief Chains: Practices, Challenges and Opportunities. International Journal Production Economics 126: 22-34. [CrossRef]

Banomyong, Ruth, Paitoon Varadejsatitwong, and Richard Oloruntoba. 2019. A systematic review of humanitarian operations, humanitarian logistics and humanitarian supply chain performance literature 2005 to 2016. Annals of Operations Research 283: 71-86. [CrossRef]

Battista, Claudia, and Massimiliano M. Schiraldi. 2013. The Logistic Maturity Model: Application to a Fashion Company. International Journal of Engineering Business Management 5: 1-11. [CrossRef]

Bitektine, Alex. 2008. Prospective case study design: qualitative method for deductive theory testing. Organizational Research Methods 11: 160-80. [CrossRef]

Brzoska, Michael. 2019. Understanding the disaster-Migration-Violent conflict nexus in a warming world: the importance of International Policy Interventions. Social Sciences 8: 167. [CrossRef]

Charles, Aurelie, Matthieu Lauras, and Luk Van Wassenhove. 2010. A model to define and assess the agility of supply chains: building on humanitarian experience. International Journal of Physical Distribution \& Logistics Management 40: 722.

Cheshmberah, Mohsen, and Safoura Beheshtikia. 2020. Supply Chain Management Maturity: An All-Encompassing Literature Review on Models, Dimensions and Approaches. Scientific Journal of Logistics 16: 103-16. [CrossRef]

Choo, Kyung-Su, Dong-Ho Kang, and Byung-Sik Kim. 2020. Impact Assessment of Urban Flood on Traffic Disruption using Rainfall-Depth-Vehicle Speed Relationship. Water 12: 926. [CrossRef]

Comfort, Louise K., Namkyung Oh, and Gunes Ertan. 2009. The Dynamics of Disaster Recovery: Resilience and Entropy in Hurricane Response Systems 2005-2008. Public Organization Review 9: 309-23. [CrossRef]

CP Team, CMMI Product. 2002. Capability Maturity Model@integration (CMMI SM), version 1.1. CMMI for Systems Engineering, Software Engineering, Integrated Product and Process Development, and Supplier Sourcing. Technical Report. Pittsburg: Carnegie Mellon University, Software Engineering Institute.

Crawford, J. Kent. 2014. Project Management Maturity Model, 3rd ed. Boca Raton: Auerbach Publications.

Curtis, Bill, Bill Hefley, and Sally Miller. 2009. People Capability Maturity Model (P-CMM) Version 2.0 (No. CMU/SEI-2009-TR-003). Pittsburg: Carnegie Mellon University, Software Engineering Institute. 
De Bruin, Tonia, Michael Rosemann, Ronald Freeze, and Uday Kaulkarni. 2005. Undertaining the Main Phases of Developing a Maturity Assessment Model. Paper presented at 16th Australasian Conference on Information Systems, Sydney, Australia, November 29-December 2.

Dijkzeul, Dennis, Dorothea Hilhorst, and Peter Walker. 2013. Introduction: evidence-based action in humanitarian crises. Disasters 37: S1-S19. [CrossRef] [PubMed]

Eisenhardt, Kathleen M. 1989. Building theories from case study research. Academy of Management Review 14: 532-50. [CrossRef]

Facchini, Francesco, Joanna Oleśków-Szłapka, Luigi Ranieri, and Andrea Urbinati. 2019. A Maturity Model for Logistics 4.0: An Empirical Analysis and a Roadmap for Future Research. Sustainability 12: 86. [CrossRef]

Fatemi, Md, Seth Asare Okyere, Stephen Kofi Diko, Michihiro Kita, Motoki Shimoda, and Shigeki Matsubara. 2020. Physical Vulnerability and Local Responses to Flood Damage in Peri-Urban Areas of Dhaka, Bangladesh. Sustainability 12: 3957. [CrossRef]

Gammelgaard, Britta. 2017. The qualitative case study. The International Journal of Logistics Management 28: 1387-424. [CrossRef]

Gonzalez-Feliu, Jesus. 2018. Sustainability evaluation of green urban logistics systems: Literature overview and proposed framework. In Green Initiatives for Business Sustainability and Value Creation. Pennsylvania: IGI Global, pp. 103-34.

Gonzalez-Feliu, Jesus, and Joelle Morana. 2010. Are city logistics solutions sustainable? The Cityporto case. Journal of Land Use, Mobility and Environment 3: 55-64.

Gonzalez-Feliu, Jesus, and Joëlle Morana. 2011. Collaborative transportation sharing: from theory to practice via a case study from France. In Technologies for Supporting Reasoning Communities and Collaborative Decision Making: Cooperative Approaches. Edited by John K. Yearwood and Andrew Stranieri. Pennsylvania: IGI Global, pp. 252-71.

Gonzalez-Feliu, Jesus, Mario Chong, Jorge Vargas Florez, and Julio Padilla Solis, eds. 2019. Handbook of Research on Urban and Humanitarian Logistics. Pennsylvania: IGI Global.

Gotham, Kevin Fox, and Richard Campanella. 2013. Constructions of resilience: ethnoracial diversity, inequality, and post-Katrina recovery, the case of New Orleans. Social Sciences 2: 298-317. [CrossRef]

Griffith, Daniel A., Bradley Boehmke, Randy V. Bradley, Benjamin T. Hazen, and Alan W. Johnson. 2019. Embedded analytics: Improving decision support for humanitarian logistics operations. Annals of Operations Research 283: 247-65. [CrossRef]

Gutiérrez, Elena Valentina, Sebastian Cortés Zapata, and Juan Sebastián Jaén. 2019. Assessment of Logistics Capabilities Maturity of Home Healthcare Providers: Case of Study for a Metropolitan Area in Colombia. In Handbook of Research on Urban and Humanitarian Logistics. Edited by Jesus Gonzalez-Feliu, Mario Chong, Jorge Vargas-Florez and Julio Alejandro Padilla-Solis. Pennsylvania: IGI Global, pp. 121-42.

Herbsleb, James, David Zubrow, Dennis Goldenson, Will Hayes, and Mark Paulk. 1997. Software quality and the capability maturity model. Communications of the ACM 40: 30-40. [CrossRef]

Holguín-Veras, José, Miguel Jaller, Luk N. Van Wassenhove, Noel Pérez, and Tricia Wachtendorf. 2012. On the unique features of post-disaster humanitarian logistics. Journal of Operations Management 30: 494-506. [CrossRef]

Holguín-Veras, José, Miguel Jaller, Luk N. Van Wassenhove, Noel Pérez, and Tricia Wachtendorf. 2014. Material convergence: Important and understudied disaster phenomenon. Natural Hazards Review 15: 1-12. [CrossRef]

Kerzner, Harold. 2002. Strategic Planning for Project Management Using a Project Management Maturity Model. Hoboken: John Wiley \& Sons.

Klaufus, Christien, and Paul Van Lindert. 2012. Informal Housing. International Encyclopedia of Housing and Home, 70-77. [CrossRef]

Kovács, Gyöngyi, and Karen M. Spens. 2007. Humanitarian logistics in disaster relief operations. International Journal of Physical Distribution E Logistics Management 37: 99.

Kunz, Nathan, and Gerald Reiner. 2012. A meta-analysis of humanitarian logistics research. Journal of Humanitarian Logistics and Supply Chain Management 2: 116-47. [CrossRef]

L'Hermitte, Cécile, Marcus Bowles, Peter H. Tatham, and Benjamin Brooks. 2018. Bridging Research and Practice in Humanitarian Logistics: A diagnostic Tool to Assess Organizational Agility. In The Palgrave Handbook of Humanitarian Logistics and Supply Chain Management. Edited by Gyöngyi Kovács, Karen Spens and Mohammad Moshtari. London: Palgrave Macmillan. [CrossRef] 
Laguna-Salvadó, Laura Laguna, Matthieu Lauras, Tina Comes, and Bartel Van de Walle. 2015. Towards More Relevant Research on Humanitarian Disaster Management Coordination. In Researching Crisis: Methodologies, Proceedings of the ISCRAM 2015 Conference-Kristiansand, 24-27 May. Edited by Leysia Palen, Monika Büscher, Tina Comes and Amanda Lee Hughes. Ocean City: International Association for Information Systems for Crisis Response and Management.

Laguna-Salvadó, Laura, Matthieu Lauras, Uche Okongwu, and Tina Comes. 2019. A multicriteria Master Planning DSS for a sustainable humanitarian supply chain. Annals of Operations Research 283: 1303-43. [CrossRef]

Lambert, Douglas M., and Martha C. Cooper. 2000. Issues in supply chain management. Industrial Marketing Management 29: 65-83. [CrossRef]

Lauras, Matthieu. 2018. Humanitarian Supply Chain Channels: From Effective to Sustainable Operations. Bogota: V Congreso Internacional Industria, Organizaciones y Logística: Industria y Logística para el Desarrollo.

Lee, Gwanhoo, and Young Hoon Kwak. 2012. An open government maturity model for social media-based public engagement. Government Information Quarterly 29: 492-503. [CrossRef]

Lee, Eui Hoon, Joong Hoon Kim, Yeon Moon Choo, and Deok Jun Jo. 2018. Application of flood nomograp for flood forecasting in urban areas. Water 10: 53. [CrossRef]

Leiras, Adriana, Irineu de Brito Jr., Eduardo Queiroz Peres, Tábata Rejane Bertazzo, and Hugo Tsugunobu Yoshida Yoshizaki. 2014. Literature review of humanitarian logistics research: trends and challenges. Journal of Humanitarian Logistics and Supply Chain Management 4: 95-130. [CrossRef]

Liyuan, Shang, and Tam Qingmei. 2014. Super network and entropy theory in quantitative decision-making of emergency logistics. Paper presented at 5th IEEE International Conference on Software Engineering and Service Science (ICSESS), Beijing, China, June 27-29; pp. 897-903.

Mallek-Daclin, Sihem, Nicolas Daclin, Gilles Dusserre, Bruno Lhéritier, Jean Blanchard, and Isabelle Arnaud. 2017. Maturity model-driven assessment of Field Hospitals. IFAC-Papers OnLine 50: 4642-47. [CrossRef]

Morana, Joëlle. 2015. La logistique urbaine durable de demain. Logistique E Management 23: 7-19.

Morana, Joëlle, and Jesus Gonzalez-Feliu. 2015. A sustainable urban logistics dashboard from the perspective of a group of operational managers. Management Research Review 38: 1068. [CrossRef]

Natarajarathinam, M., Ismail Capar, and Arunachalam Narayanan. 2009. Managing supply chains in times of crisis: A review of literature and insights. International Journal of Physical Distribution and Logistics Management 39: 535-73. [CrossRef]

Osorio-Ramirez, Carlos. 2017. Mecanismos de Coordinación para la Optimización del Desempeño de la Cadena Logística Humanitaria Mediante Modelamiento Estocástico. Caso Colombiano. Ph.D. thesis, Universidad Nacional de Colombia, sede Bogota, Facultad de Ingeniería, Bogotá, Colombia.

Overstreet, Robert E., Dianne Hall, Joe B. Hanna, and R. Kelly Rainer. 2011. Research in humanitarian logistics. Journal of Humanitarian Logistics and Supply Chain Management 1: 114-31. [CrossRef]

Paulk, Mark C., Bill Curtis, Mary Beth Chrissis, and Charles V. Weber. 1993. Capability Maturity Model, Version 1.1. IEEE Software 10: 18-27. [CrossRef]

Peres, Eduardo Queiroz, Irineu de Brito Jr., Adriana Leiras, and Hugo Yoshizaki. 2012. Humanitarian logistics and disaster relief research: Trends, applications, and future research directions. Paper presented at the 4th International Conference on Information Systems, Logistics and Supply Chain, Bordeaux, France, June 1-4; pp. 26-29.

Piaget, Jean. 1971. The Theory of Stages in Cognitive Development. In Measurement and Piaget. Edited by Dondal Ross Green, Marguerite P. Ford and George B. Flamer. New York: McGraw-Hill, pp. 1-11.

Piatyszek, Eric, Alicja Tardy, Michel Lesbats, and Ana Maria Cruz. 2017. Natech events triggered by floods: When floods cause technological accidents. In Floods. Amsterdam: Elsevier, pp. 73-87.

Potage, Jean. 1998. Les achats à Thomson-CSF, vers un nécessaire modèle de maturité. Revue Internationale de l'achat 18: 11-18.

Potage, Jean. 2017. Managing procurement value creation with a maturity model. Logistique $\mathcal{E}$ Management 25: 303-15.

Rosemann, Michael, and Tonia de Bruin. 2005. Towards a business process management maturity model. In Paper presented at 2005 Proceedings of the Thirteenth European Conference on Information Systems, Long Beach, CA, USA, August 10-13; pp. 26-28.

Ruel, Salomée. 2019. Freins à la mutualisation horizontale: Enseignements d'une étude de cas dans le secteur agroalimentaire. Logistique \& Management 27: 119-31. 
Salam, Mohammad Asif, and Sami A. Khan. 2020. Lessons from the humanitarian disaster logistics management. Benchmarking: An International Journal. in press. [CrossRef]

Salazar-Briones, Carlos, José Mizael Ruiz-Gibert, Marcelo A. Lomelí-Banda, and Alejandro Mungaray-Moctezuma. 2020. An Integrated Urban Flood Vulnerability Index for Sustainable Planning in Arid Zones of Developing Countries. Water 12: 608. [CrossRef]

UN OCHA. 2016. El Niño: Overview of Impact, Projected Humanitarian Needs and Response as of 02 June 2016. New York: United Nations Office for the Coordination of Humanitarian Affairs.

Varella, Leonardo, and Miriam B. Gonçalves. 2016. Collaboration: A critical success factor in the logistics of Donations Management. Available online: https://pdfs.semanticscholar.org/4b82/0cd1148b09fa76fa672f1661233e3ed90f8b. pdf?_ga=2.80488855.1229516843.1590587312-273105443.1590587312 (accessed on 11 April 2020).

Vargas-Florez, Jorge. 2017. Conception de Chaînes Logistiques Humanitaires. Sarrebruck: Presses Académiques Francophones.

Vargas-Florez, J., Matthieu Lauras, Lionel Dupont, and Aurélie Charles. 2013. Towards a demand forecast methodology for recurrent disasters. WIT Transactions on the Built Environment 133: 99-110.

Vega, D. 2018. Case studies in humanitarian logistics research. Journal of Humanitarian Logistics and Supply Chain Management 8: 134-52. [CrossRef]

Wendler, Roy. 2012. The maturity of maturity model research: A systematic mapping study. Information and Software Technology. [CrossRef]

Wu, Liusan, Qingmei Tan, and Yuehui Zhang. 2013. Network connectivity entropy and its application on network connectivity reliability. Physica A Statistical Mechanics and its Application 392: 5536-41. [CrossRef]

Xu, Dingde, Linmei Zhuang, Xin Deng, Cheng Qing, and Zhuolin Yong. 2020. Media Exposure, Disaster Experience, and Risk Perception of Rural Households in Earthquake-Stricken Areas: Evidence from Rural China. International Journal of Environmental Research and Public Health 17: 3246. [CrossRef]

Yin, Robert K. 2018. Case Study Research and Applications: Design and Methods, 6th ed. Thousand Oaks: SAGE Publications.

(C) 2020 by the authors. Licensee MDPI, Basel, Switzerland. This article is an open access article distributed under the terms and conditions of the Creative Commons Attribution (CC BY) license (http://creativecommons.org/licenses/by/4.0/). 